\title{
QUEEN'S
UNIVERSITY
BELFAST
}

\section{Localization of the zinc binding tubulin polymerization promoting protein in the mice and human eye}

Tripon, R. G., Oláh, J., Nasir, T., Csincsik, L., Li, C. L., Szunyogh, S., Gong, H., Flinn, J. M., Ovádi, J., \& Lengyel, I. (2017). Localization of the zinc binding tubulin polymerization promoting protein in the mice and human eye. Journal of trace elements in medicine and biology : organ of the Society for Minerals and Trace Elements (GMS). https://doi.org/10.1016/j.jtemb.2017.12.009

Published in:

Journal of trace elements in medicine and biology : organ of the Society for Minerals and Trace Elements (GMS)

Document Version:

Peer reviewed version

Queen's University Belfast - Research Portal:

Link to publication record in Queen's University Belfast Research Portal

Publisher rights

Copyright 2018 Elsevier.

This manuscript is distributed under a Creative Commons Attribution-NonCommercial-NoDerivs License

(https://creativecommons.org/licenses/by-nc-nd/4.0/), which permits distribution and reproduction for non-commercial purposes, provided the author and source are cited.

\section{General rights}

Copyright for the publications made accessible via the Queen's University Belfast Research Portal is retained by the author(s) and / or other copyright owners and it is a condition of accessing these publications that users recognise and abide by the legal requirements associated with these rights.

Take down policy

The Research Portal is Queen's institutional repository that provides access to Queen's research output. Every effort has been made to ensure that content in the Research Portal does not infringe any person's rights, or applicable UK laws. If you discover content in the Research Portal that you believe breaches copyright or violates any law, please contact openaccess@qub.ac.uk. 


\section{Localization of the Zinc Binding Tubulin Polymerization Promoting Protein in the Mice and Human Eye}

Robert G. Tripon ${ }^{a, b}$, Judit Oláh ${ }^{c}$, Tajwar Nasira ${ }^{a}$ Lajos Csincsik ${ }^{a, d}$, Chee Lok Li ${ }^{a}$, Sándor Szunyoghc, Haiyan Gong ${ }^{\mathrm{e}}$, Jane M. Flinn ${ }^{f}$, Judit Ovádic, Imre Lengyela,d*

aUCL Institute of Ophthalmology, University College London, London, EC1Y 8TB, UK; ' bepartment of Histology, University of Medicine and Pharmacy, Tîrgu Mureş, Romania; 'Institute of Enzymology, Research Centre for Natural Sciences, Hungarian Academy of Sciences, Budapest, 1117, Hungary; 'Center of Experimental Medicine, The Queen's University Belfast, BT9 7BL, UK; 'Department of Ophthalmology, Boston University School of Medicine, MA, USA; fDepartment of Psychology, George Mason University Fairfax, VA, USA

Judit Oláh: olah.judit@ttk.mta.hu; Robert G. Tripon: robert.tripon@umftgm.ro; Tajwar Nasir: tajwar.nasir.12@ucl.ac.uk; Lajos Csincsik: Lcsincsik01@qub.ac.uk; Chee Lok Li: chee.li.13@alumni.ucl.ac.uk; Sándor Szunyogh: szunyogh.sandor@ttk.mta.hu; Haiyan Gong: hgong@bu.edu; Jane M. Flinn: jflinn@gmu.edu; Judit Ovádi: ovadi.judit@ttk.mta.hu; Imre Lengyel: i.lengyel@qub.ac.uk;

Short title: TPPP/p25 in the retina

*To whom correspondence should be addressed: Imre Lengyel, Room 01.057, The Wellcome-Wolfson Building Centre for Experimental Medicine, School of Medicine, Dentistry and Biomedical Science, Queen's University Belfast, 97 Lisburn Road, Belfast BT9 7BL, UK. Telephone: +44 (0) 289097 6027, E-mail: i.lengyel@qub.ac.uk 


\section{Highlights}

- TPPP/p25 is expressed in oligodendrocytes and some amacrine cell bodies in the eye

- In the inner plexiform layer of the retina TPPP/p25 is expressed in postsynaptic dendrites

- Zinc supplementation elevates the levels of TPPP/p25 in the inner plexiform layer

- Zinc could play a role in the integration of visual stimulus in the retina

\section{Graphical abstract}

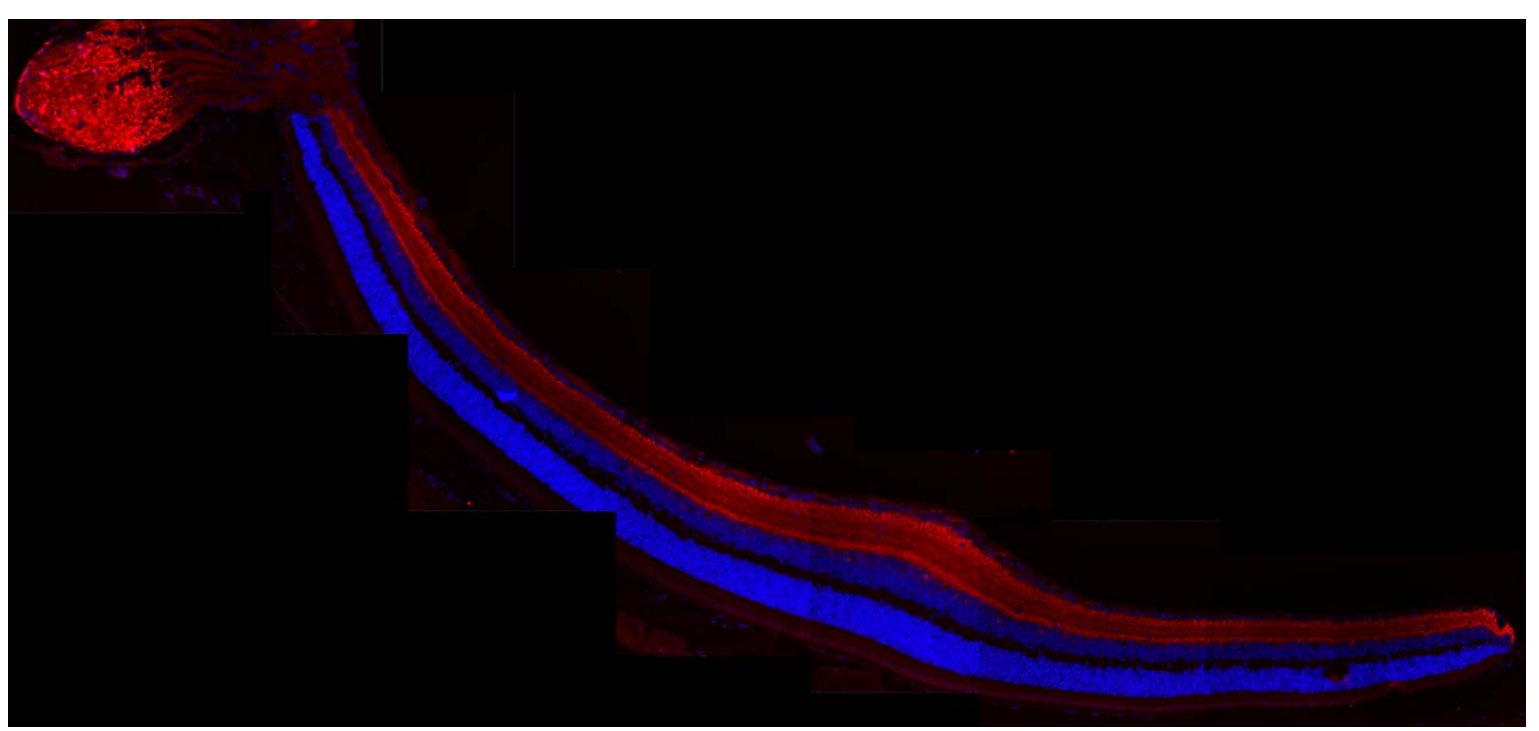




\section{ABSTRACT}

Tubulin Polymerization Promoting Protein (TPPP/p25) modulates the dynamics and stability of the microtubule network by its bundling and acetylation enhancing activities that can be modulated by the binding of zinc to TPPP/p25. Its expression is essential for the differentiation of oligodendrocytes, the major constituents of the myelin sheath, and has been associated with neuronal inclusions. In this paper, evidence is provided for the expression and localization of TPPP/p25 in the zinc-rich retina and in the oligodendrocytes in the optic nerve. Localization of TPPP/p25 was established by confocal microscopy using calbindin and synaptophysin as markers of specific striations in the inner plexiform layer (IPL) and presynaptic terminals, respectively. Postsynaptic nerve terminals in striations S1, S3 and S5 in the IPL and a subset of amacrine cells show immunopositivity against TPPP/p25 both in mice and human eyes. The co-localization of TPPP/p25 with acetylated tubulin was detected in amacrine cells, oligodendrocyte cell bodies and in synapses in the IPL. Quantitative Western blot revealed that the TPPP/p25 level in the retina was $0.05-0.13 \mathrm{ng} / \mathrm{\mu g}$ protein, comparable to that in the brain. There was a central (from optic nerve head) to peripheral retinal gradient in TPPP/p25 protein levels. Our in vivo studies revealed that the oral zinc supplementation of mice significantly increased TPPP/p25 as well as acetylated tubulin levels in the IPL. These results suggest that TPPP/p25, a microtubule stabilizer can play a role in the organization and reorganization of synaptic connections and visual integration in the eye.

Keywords: Tubulin Polymerization Promoting Protein, retina, inner plexiform layer, amacrine cell, zinc, myelin sheath 


\section{INTRODUCTION}

Tubulin Polymerization Promoting Protein (TPPP/p25) is a 25 kDa disordered microtubule-associated protein that was first identified in the brain [1] where it plays a crucial role in the differentiation of oligodendrocytes [2] and is involved in the development, maintenance and stability of oligodendrocyte projections due to the modulation of the dynamics and stability of microtubule network [3-5]. Oligodendrocytes are the major constituents of the myelin sheath. TPPP/p25 directly interacts with histone deacetylase 6, inhibits its activity, and therefore regulates acetylation of tubulin [5] and influence differentiation, cellular polarization and migration [6-9].

While the normal function of TPPP/p25 is to modulate and stabilize the microtubule network [3-5] by it bundling and acetylation enhancing activity due to its interaction with tubulin deacetylases (histone deacetylase 6, sirtuin 2), it can also directly interact with $\alpha$-synuclein [10], hallmark protein of synucleinopathies, and play a role in its pathological oligomerisation/aggregation. TPPP/p25 is implicated in the development of synucleinopathies such as Parkinson's disease and Multiple System Atrophy, when $\alpha$-synuclein and TPPP/p25 are co-localized and co-enriched in the inclusions $[11-14]$

TPPP/p25 has a zinc binding motif $[15,16]$, the specific binding of the bivalent zinc cation to TPPP/p25 induces structural changes/dimerization coupled with stabilization that counteracts its proteolytic degradation [17]. Thus, zinc may control the intracellular level of TPPP/p25, playing role in its physiological as well as its pathological functions [17]. Zinc levels can be altered in different diseases of the eye [18] and a recent study showed that optic nerve $(\mathrm{ON})$ injuries can elevate zinc levels not only in the ON but also in the retina [19]. In this paper, we set out to investigate whether the intracellular TPPP/p25 level could be affected by the zinc level. 


\section{MATERIALS AND METHODS}

Antibodies - The list of antibodies used for the experiments can be found in Supplementary Table 1.

Human eyes - Five whole human eyes with no known pathological conditions were obtained from the Boston University and the UCL Institute of Ophthalmology Eye Depositories within 24 hours of death. In addition, paraffin sections from six eyes from the UCL Institute of Ophthalmology pathological archive were also used. Full Local Research Ethics Committee approval and appropriate consent was obtained in each case. The protocol of the study adhered to the tenets of the Declaration of Helsinki regarding research involving human tissue.

Mouse eyes - Eyes from 6 months old female mice were used in this study from a previous experiment in which zinc supplementation had a significant behavioural effect [20]. The eyes were dissected from double transgenic mice overexpressing human APP and ApoE4 as well as wild type litter mates [20]. Four wild type and 4 transgenic animals were given drinking water without zinc supplementation to establish baseline. In addition, 4 transgenic mice were given drinking water supplemented with $10 \mathrm{ppm}$ (0.153 mM) zinc carbonate from the age of 2 months The zinc-enhanced water was prepared by dissolving $10,000 \mathrm{mg} / \mathrm{L}$ zinc in $5 \% \mathrm{HNO}_{3}$ and adding $\mathrm{Na}_{2} \mathrm{CO}_{3}$ to buffer the solution to $\mathrm{pH} 7.0[20]$.

Preparation of human retina extract - Cell extracts were prepared from three unfixed human eyes that were flat mounted before peripheral and central retina tissues were 
excised. After excision, the tissues were homogenized in buffer A (10 mM tris(hydroxymethyl)aminomethane, $150 \mathrm{mM} \mathrm{NaCl}, 5 \mathrm{mM}$ ethylenediaminetetraacetic acid $\mathrm{pH}$ 7.4 containing $1 \mu \mathrm{g} / \mathrm{ml}$ leupeptin, $1 \mu \mathrm{g} / \mathrm{ml}$ pepstatin, $10 \mu \mathrm{M}$ 4-(2-aminoethyl) benzenesulfonyl fluoride hydrochloride, $1 \mathrm{mM}$ benzamidine, $1 \%$ Triton $\mathrm{X}-100$ ) at a 1:4 ratio of tissue and buffer by a Potter-homogenizer. The homogenates were centrifuged at $17000 \mathrm{~g}$ for $10 \mathrm{~min}$ at $4^{\circ} \mathrm{C}$, and the supernatants were used for further experiments. Bovine brain extract was prepared similarly. The protein concentration of the retina/brain extract was determined by the Bradford method [21] using the Bio-Rad protein assay kit.

Purification of human wild type TPPP/p25 and bovine tubulin - Human recombinant full length TPPP/p25 with a His-tag was expressed in E. coli BL21 (DE3) cells and isolated on HIS-Select ${ }^{\mathrm{TM}}$ Cartridge (Sigma-Aldrich) as described previously $[11,22]$. Tubulin was prepared from bovine brain according to the method of $\mathrm{Na}$ and Timasheff [23]. TPPP/p25 concentration was determined from the absorbance at $280 \mathrm{~nm}$ using an extinction coefficient of $10095 \mathrm{M}^{-1}{ }^{*} \mathrm{~cm}^{-1}$.

Western blot - Retina samples were analysed by sodium dodecyl sulphate polyacrylamide gel electrophoresis, and were electrotransferred onto Immobilon-PSQ transfer membranes and labelled with antibodies: TPPP/p25 in a dilution of 1:5000 [11] or with tubulin (1:5000; Sigma T9026), acetylated tubulin (1:5000; Sigma T6793) or glyceraldehyde-3-phosphate dehydrogenase (GAPDH) in mouse (1:25000 Calbiochem CB1001) (Supplementary Table 1). Antibody binding was revealed by using anti-rat or anti-mouse IgG coupled with peroxidase, ECL® (enhanced chemiluminescence) Western Blotting Detection reagents (Amersham Biosciences) and Chemidoc Image 
system or 3-amino-9-ethylcarbazole as substrate. Images were analysed by Image-J using mean pixel intensity value tool kit.

Immunocytochemistry - Eyes from human as well as mice were embedded in paraffin and $10 \mu \mathrm{m}$ sections were collected on glass slides. Immunohistochemistry was performed using monoclonal and polyclonal antibodies against several relevant proteins (see list in Supplementary Table 1). Primary antibodies were applied after antigen retrieval in citrate buffer (heating for $2 \times 3$ minutes for mice and $3 \times 3$ minutes for human samples in microwave at $750 \mathrm{~W})$ followed by blocking for 1 hour in goat serum (1:20, Sigma G9023). Primary and secondary antibodies were applied for 1 hour at room temperature, washed $3 \times 5$ min with phosphate buffer saline (PBS). TPPP/p25 was visualized using Alexa-Fluor 488 Goat anti-rat secondary antibody (1:1000; Invitrogen A11006). Acetylated tubulin, calbindin and synaptophysin labelling were visualized using Alexa-Fluor 568 Goat anti-mouse secondary antibodies (1:1000; Sigma T7782). Nuclear staining was performed using Hoechst $(0.001 \mathrm{~g} / \mathrm{ml}$, Life Technologies H3570). Samples were imaged using a Zeiss LSM700 confocal microscope through 40x or 63x/1.2 NA Zeiss Neofluar objectives and images generated using the ZEN software package (Zeiss). Central and peripheral retinal images were taken from each section. Sections from lab water or zinc fed animals were processed in parallel and microscope setting was kept standard between samples for the comparison of immunofluorescence intensities. Images were imported into Image-J and fluorescence intensities were analysed using mean pixel intensity value tool kit.

Immunogold staining - Retina from an unfixed human eye was flat mounted and fixed in $3 \%$ formaldehyde and $0.2 \%$ glutaraldehyde overnight at $4^{\circ} \mathrm{C}$, then washed in PBS. 
The macular region was dissected and embedded in $3.6 \%$ agarose solution and vibratome sections of $50 \mu \mathrm{m}$ thickness were cut and collected in a 24 well plate in PBS. To visualize ultrastructural localization of TPPP/p25 in the retina, sections were processed for pre-embedding immunogold labelling using methods modified from [24, 25]. The sections were washed in $50 \mathrm{mM}$ glycine solution for 2 hours, then incubated in 10 mM sodium citrate buffer ( $\mathrm{pH}$ 6.0) for 15 mins using a variable wattage microwave (power at 200 Watts, sample temperature at $45^{\circ} \mathrm{C}$; Pelco BioWave, Ted Pella) for antigen retrieval. After rinsing (3×10 mins in PBS), sections were incubated in blocking solution ( $10 \%$ bovine serum albumin (BSA), $5 \%$ normal goat serum (NGS), $0.025 \%$ Triton-X in PBS) for 1 hour at room temperature. Sections were incubated with the rabbit polyclonal primary antibody against TPPP/p25 (1:100, Novusbio NBP1-80962), first in the microwave $\left(5\right.$ mins at $\left.150 \mathrm{~W}, 35^{\circ} \mathrm{C}\right)$ and then at $4^{\circ} \mathrm{C}$ overnight. Sections were rinsed (3x10 mins in $10 \mathrm{mM}$ phosphate buffer with $0.2 \%$ Aurion BSA-c) and then incubated in a $6 \mathrm{~nm}$ gold-conjugated goat anti-rabbit secondary FAB2 IgG (1:50, Aurion) in the microwave $\left(5\right.$ mins at $\left.150 \mathrm{~W}, 35^{\circ} \mathrm{C}\right)$, followed by incubation overnight at $4^{\circ} \mathrm{C}$. The antibody was diluted in PBS, $0.2 \%$ acetylated BSA (BSA-c; Aurion) and $0.025 \%$ TritonX. After antibody incubation steps, sections were rinsed in PBS with $0.2 \%$ BSA-c, followed by quick rinses in $20 \mathrm{mM}$ sodium citrate buffer ( $\mathrm{pH} 7.0,5 \mathrm{mins})$ then distilled water (1 $\mathrm{min})$. Sections were then processed for silver enhancement of gold-particles, using R-Gent SE-EM kit (Aurion; 60-90 mins), for better visualization of gold label. After rinses in water and PBS, sections were post-fixed in $6 \%$ glutaraldehyde and $2 \%$ paraformaldehyde solution. Samples were heated in a microwave until sample temperatures reached $30^{\circ} \mathrm{C}(4 \times 5 \mathrm{~min} 200 \mathrm{~W})$. The labelled retina samples were osmicated in $1 \%$ osmium solution for 30 minutes at room temperature, incubated in $1.5 \%$ aqueous uranyl acetate solution for 90 mins, dehydrated and embedded in Epon-Araldite resin. 
Ultra-thin sections of 70-90 $\mathrm{nm}$ thickness were cut and collected on pioloform coated copper slot grids. The samples were imaged using at 80kV JOEL JEM-1010 transmission electron microscope.

Statistical analysis - Representative experiments were analysed using Wilcoxon matched-pairs signed rank test to determine differences between two groups. When more than two groups were analysed two results were compared with 2-way ANOVA. $p$-values of less than 0.05 were considered significant: ${ }^{*} p<0.05$. 


\section{RESULTS}

\section{TPPP/p25 in the mouse eye}

First, we determined the immunolocalization of TPPP/p25 in the ON in mice eyes. The myelin sheath around the ON axons is formed by oligodendroglia and TPPP/p25 has been shown to be present and play a crucial role in the differentiation of oligodendrocytes in the brain [2]. As predicted, there was a strong immunopositivity for TPPP/p25 present in oligodendrocytes in the ON (Fig. 1). We found strong TPPP/p25 labelling in the myelinated portion of the ON (Fig. 1A1), where the labelling was associated with cell bodies and structures resembling oligodendrocytes and fibres, respectively (Fig. 1A2, insert). Immunolabelling was terminated close to the entry of $\mathrm{ON}$ into the eye (Fig. 1A1) at the area known to be devoid of myelin [26] due to the presence of the lamina cribrosa that prevents the entry of oligodendrocyte precursor cells into the eye to prevent interference with light processing $[27,28]$. These observations on mice ON provided support for the specificity of the antibodies we used in our experiments.

TPPP/p25 was localized to the inner plexiform layer (IPL) (Fig 1A1 and 1B2) in sublamina S1, S3 and S5 as distinct puncta (Fig. 1C). The area occupied by the different TPPP $/ p 25$ striations were $\mathrm{S} 1=0-22 \%, \mathrm{~S} 2=23-29 \%, \mathrm{~S} 3=30-52 \%, \mathrm{~S} 4=53-60 \%$ and S5 $=61-100 \%$ where S1 was the closest to the inner nuclear layer (INL) and S5 to the ganglion cell layer (GCL) (Supplementary Table 2). The full width of the IPL was $100 \%$. To confirm the definition of S2 and S4, we co-labelled sections with a calbindin specific antibody. Calbindin has been previously shown to localize to S2, S3 and S4 only [29, 30]. Clearly, the labelling of calbindin interposes between the TPPP/p25 labelled sublaminas in S2 and S4 and co-localizes in S3 (Fig. 1G1-3). TPPP/p25 was enriched in a small subset of cell bodies in the INL and GCL in cells immediately adjacent to the IPL (Fig. 1 B2, C, F1 and G1). We also found TPPP/p25 immunopositive interplexiform 
projections to the outer plexiform layer (OPL) through the INL (Fig. $1 \mathrm{D}$, arrow). Due to the punctate appearance of TPPP/p25 immunolabelling in the IPL we speculated that the protein was associated with presynaptic terminals. To determine whether this localization is pre- or postsynaptic we co-labelled sections with TPPP/p25 (Fig. 1F1) and the presynaptic marker synaptophysin (Fig. 1F2). The lack of co-localization (Fig. 1F3) suggested that TPPP/p25 is likely to be associated with postsynaptic boutons. This was most evident in the sublamina S5, where anti-synaptophysin positive nerve endings were surrounded by TPPP/p25 positive structures (see supplementary Fig. S2). TPPP/p25 is involved in tubulin acetylation, therefore, we also assessed whether there is co-localization of TPPP/p25 and acetylated tubulin in the mouse eye. Acetylated tubulin immunoreactivity was present in the ON as well as in the IPL (Fig. 1A1) but it appeared that there are areas where there was a lack of co-localization (Fig 1E1-3). Acetylated tubulin immunoreactivity was associated with discrete filamentous structures in the IPL (Fig. 1B3 and E2; Supplementary figure S1) adjacent to the punctate labelling of TPPP/p25. Acetylated tubulin labelling was the strongest in sublamina S1 and then uniformly distributed in S2-S5 (See supplementary Fig. S1 and Supplementary Table 2). Acetylated tubulin immunoreactivity was present throughout the retina (Supplementary figure S1).

To examine further the co-localization of TPPP/p25 and acetylated tubulin, we generated line scans across the areas of interest (Fig 2). On the ON, there is clear and strong co-localization between the two proteins (Fig 2A). In the retina, there are areas with full co-localization, but there are areas in which only TPPP/p25 or acetylated tubulin was present (Fig 2B, arrow heads).

Effect of zinc supplementation on TPPP/p25 level in mice 
After determining TPPP/p25 localization we explored whether experimental manipulation influences TPPP/p25 levels. It has been reported that zinc induced structural rearrangement of TPPP/p25 into the so called molten globule [15], increased TPPP/p25 levels and tubulin polymerization at cellular level $[16,17]$. Zinc is abundantly present in the retina [31] and zinc supplementation has a direct effect on the eye [32]. In addition, recent evidence shows ON injury can significantly increase zinc levels, especially in the IPL [19]. Therefore, we examined whether supplementation with zinc could affect TPPP/p25 and/or tubulin acetylation in the mouse eyes. We found that long term zinc supplementation has a lasting effect by significantly increasing TPPP/p25 immunoreactivity (Fig. 3A) as well as acetylated tubulin immunoreactivity (Fig 3B) in the IPL. These effects appear only to be significant in the central but not in the peripheral retina (Fig. 3). While the number of sample were low $(n=3)$ to fully assess the sub-laminar changes the immunoreactivity of TPPP/p25 was increased in all striations, while acetylated tubulin immunoreactivity appeared to increase only in S1 (Supplementary Table 2).

\section{Localization of TPPP/p25 in the human retina}

Localization of TPPP/p25 in the human retina was carried out by labelling fixed and sectioned samples from 5 independent human cadaveric eyes with two different polyclonal antisera. TPPP/p25 immunopositivity was present in the IPL in sublamina S1, S3 and S5 forming distinct puncta (Fig. 4A). Cytosolic labelling was observed in a subset of neuronal cells immediately adjacent to the IPL in the GCL as well as the INL (Fig. 4B, white arrows) with occasional interplexyform projections to the OPL (Fig 4B, red arrow). Imaging flat-mount retinas we found that $<7 \%$ of the total numbers of cell (determined by counting labelled nuclei and immunopositive cells) adjacent to the IPL were labelled (Fig. 4C). 
Based on their location immediately adjacent to the IPL we propose that the TPPP/p25 positive cells are amacrine cells. Although the list is growing, over 45 different types of amacrine cells are identified at the inner and outer margin of the INL [30, 33]. Distinguishing amongst the major subtype of amacrine cells is possible by identifying the branching morphology or the neurotransmitter they are enriched in [30, 33]. We examined weather the cells in our experiments are GABA- or glycinergic [30, 34]. Co-labelling the retina with antisera against GABA or glycine and TPPP/p25 showed many GABA/glycine positive cells (Fig.5A and B, white arrows) but only partial co-localization with TPPP/p25 (Fig. 5 A and B; yellow/orange cell bodies). Therefore, no identification based on these neurotransmitters was found. In synaptic terminal in the IPL GABA did not co-localize with TPPP/p25 (Fig. 5C) but rather was positioned the opposing side of a synapse, suggesting, just as in mouse, that TPPP/p25 is a postsynaptic protein. To confirm its postsynaptic location human samples were labelled with immunogold for TPPP/p25 which then was silver enhanced for electron microscopy. Immunoelectron microscopy confirmed that TPPP/p25 was indeed in boutons with little or no synaptic vesicles, opposing vesicle-rich boutons (Fig 5D).

Finally, we determined the concentration of TPPP/p25 levels in the human retina using retina extracts from three freshly dissected, unfixed cadaveric samples (from donor ages 54,69 and 74 years old). After flat mounting regions from the central and peripheral retina were excised and homogenized before Western blotting (Fig. 6A). To quantify protein levels, known amounts of expressed, purified TPPP/p25 was run in parallel with the retinal samples (Fig. 6A). We found that TPPP/25 levels were in the range of 0.05-013 ng TPPP/p25 per $\mu \mathrm{g}$ of extracted total protein or 0.6-4.4 $\mu \mathrm{g}$ TPPP/p25 per gram of tissue wet weight. These levels were lower but comparable to TPPP/p25 levels in brain homogenate [3]. We found that TPPP/p25 levels were significantly lower in the 
peripheral retina compared to the central region (Fig 6A and B). Based on the association between TPPP/p25 and tubulin acetylation [5, 35], we also determined the acetylated tubulin immunoreactivity in human retinal extracts using qualitative Western blot (Fig. 6D). We found that while the total tubulin concentrations (determined by quantitative Western blot) were similar in the central and peripheral retina and had little variability between samples (Fig. 6E), acetylated tubulin levels were highly variable with a trend of lower acetylation levels in the periphery (Fig. 6D). We found no difference in GAPDH levels which was used as loading control for the experiments (Fig. 6C). 


\section{DISCUSSION}

TPPP/p25 is an oligodendrocyte specific neomorphic moonlighting protein with physiological functions involving the enhancement of acetylation and bundling of microtubules and the maintenance of the zinc-rich myelin sheath [2, 3, 5, 15-17]. In pathology, TPPP/p25 interacts with different proteins like alpha-synuclein [11, 36-38] forming inclusions $[4,11]$. As such TPPP/p25 has multitude of effects that can maintain health or lead to disease. Zinc binds to TPPP/p25 and alters its levels [15, 17]. Therefore, in tissues where changes in zinc levels play a significant role, interaction between TPPP/p25 and zinc can significantly alter its normal and/or pathological function. In the eye, especially in the retina, zinc levels are altered by light dark adaptation [39] or nerve injury [19] and this zinc could alter the levels of proteins like TPPP/p25. In this study, we found that TPPP/p25 has a selective expression in cells resembling amacrine cells and synaptic terminals in the IPL of human as well as mice. We also found that elevated zinc, though oral supplementation, can affect TPPP/p25 level, suggesting that TPPP/p25 may play a role in the organization and reorganization of retinal connection at least partly through promoting tubulin acetylation.

As expected we have detected TPPP/p25 in the oligodendrocytes in the ON as in brain tissue, but not in lamina cribrosa, which stop oligodendrocyte migration in the retina [26-28]. This observation underlines the specificity of the polyclonal and monoclonal TPPP/p25 antibodies used in this and several previous studies for the identification of TPPP/p25 in oligodendrocytes and as a hallmark protein for synucleinopathies $[5,11$, $37,38]$. 
There were two major findings in our immunohistochemical studies. We identified TPPP/p25 immunoreactivity in some but not all cell bodies at the inner and outer edges of the IPL, and we found intense punctate labelling in the IPL in striations S1, S3 and S5 both in human and mouse retina (Fig. 1 and 4). Previously TPPP/p25 was identified in other retinal layers as well $[40,41]$, which could be due to the different sampling/methodologies used in different laboratories. The cells adjacent to the IPL in the INL are amacrine cells [33], and can be classified in a number of ways into $30-46$ different subtypes based on their dendritic arborisation and neurotransmitter content [30]. Therefore, we propose that the cell bodies positive to TPPP/p25 are amacrine cells: those in the GCL are probably displace amacrine cells [42] while those with projections between the IPL and the OPL are interplexiform amacrine cells [43] (Fig 1 and 4). Some of the TPPP/p25 cells contain GABA while others contain glycine as neurotransmitter, but not all GABA or glycine positive cells contain TPPP/p25 (Fig. 5). Whether TPPP/p25 positive cells represent a new subclass of amacrine cells is yet to be determined. In the IPL TPPP/p25 appears to be postsynaptically located (Fig. 1 and 5). Lamina S5 is of special interest because enlarged presynaptic rod bipolar boutons were found to be synaptophysin rich, which are surrounded exclusively by amacrine cell processes $[44,45]$ and that is what we found in our experiments too (Supplementary Figure S2). TPPP/p25 often co-localized with acetylated tubulin (Fig. 2), which suggests that TPPP/p25 plays a role in organizing and/or reorganizing synaptic connection and as such visual integration through regulating the acetylation of the microtubule network. Our finding on TEM showed that in the IPL TPPP/p25 was in boutons containing few synaptic vesicles and not in the synaptic vesicle rich presynaptic terminals of a bipolar cell. As postsynaptic ganglion cell contains no synaptic vesicles, this finding supports the idea that TPPP/p25 positive boutons belong to amacrine cells [46]. 
Interestingly, the level of TPPP/p25 in the retina was comparable to that in the brain and higher than in most other tissues [40].

Finally, the fact that TPPP/p25 and acetylated tubulin levels are significantly altered by zinc supplementation suggest that changes in zinc levels associated to physiological [39] or pathological conditions [19] can influence the organization and reorganization of the synaptic network in the IPL. The most likely mechanism behind the increase in TPPP/p25 levels is the reported zinc involvement in stabilization of the protein [17].

\section{CONCLUSION}

We found that TPPP/p25 is localized to specific areas of the retina and that significant differences do exist between the levels of TPPP/p25 with or without oral zinc supplementation. The co-localization and simultaneous change of TPPP/p25 and acetylated tubulin by zinc supports a microtubule-related function. However, since TPPP/p25 is known to increase the aggregation of proteins like alpha-synuclein $[10,11,36]$, elevated TPPP/p25 levels may also be involved in synaptic dysfunction in the inner retina and may play a role in nerve injury [19]. Therefore, the zinc-mediated TPPP/p25 increase may contribute to normal as well as pathological conditions.

Acknowledgments: The authors thank Professors Alan C. Bird and John Dowling for helpful discussions. We are grateful to Dr Maria Medalla, Marcia Feinberg, Pietro M. Bertelli, Ruiyi Ren, Thuy Duong Le, Lihua Gong and David Swain for technical help.

Funding: The research was supported by the Bill Brown Charitable Trust Senior Research Fellowship, Moorfields Eye Hospital Special Trustees, Mercer Fund from Fight 
for Sight (I.L), The Massachusetts Lions Eye Research Fund (H.G and R.G.T.), Internal Grant for Research no. 17800 by University of Medicine and Pharmacy of Tîrgu Mureş, Romania (R.G.T.) and ARVO Foundation for Eye Research through Collaborative Research Fellowship (R.G.T). This work was supported by STSM grants from COST Action TD 1304 - the Network for the Biology of Zinc (Zinc-Net) (J.O. and R.G.T.) and the authors would like to acknowledge networking support by the COST action TD1304 (J.O, J.O, I.L, R.G.T). This work was supported by the European Cooperation in Science and Technology COST Action [CM1406] and Hungarian National Scientific Research Fund Grants OTKA [K-112144] to J. Ovádi. Tissue for this project was provided by Boston University and the UCL Institute of Ophthalmology and Moorfields Eye Hospital Eye Tissue Repository supported by NIHR funding.

List of abbreviations: bovine serum albumin, BSA; ganglion cell layer, GCL; glyceraldehyde-3-phosphate dehydrogenase, GAPDH; inner nuclear layer, INL; inner plexiform layer, IPL; optic nerve, ON; outer plexiform layer; OPL; phosphate buffered saline, PBS; retinal nerve fibre layer, RNFL; Tubulin Polymerization Promoting Protein, TPPP/p25;

Competing interests: The authors declare that they have no competing interests. 


\section{REFERENCES}

[1] M. Takahashi, K. Tomizawa, K. Ishiguro, K. Sato, A. Omori, S. Sato, A. Shiratsuchi, T. Uchida, K. Imahori, A novel brain-specific $25 \mathrm{kDa}$ protein (p25) is phosphorylated by a Ser/Thr-Pro kinase (TPK II) from tau protein kinase fractions, FEBS Lett 289(1) (1991) 37-43.

[2] A. Lehotzky, P. Lau, N. Tökési, N. Muja, L.D. Hudson, J. Ovádi, TUBULIN POLYMERIZATION PROMOTING PROTEIN (TPPP/p25) IS CRITICAL FOR OLIGODENDROCYTE DIFFERENTIATION, Glia 58(2) (2010) 157-168.

[3] E. Hlavanda, J. Kovacs, J. Olah, F. Orosz, K.F. Medzihradszky, J. Ovadi, Brain-specific p25 protein binds to tubulin and microtubules and induces aberrant microtubule assemblies at substoichiometric concentrations, Biochemistry 41(27) (2002) 8657-64.

[4] A. Lehotzky, L. Tirián, N. Tökési, P. Lénárt, B. Szabó, J. Kovács, J. Ovádi, Dynamic targeting of microtubules by TPPP/p25 affects cell survival, Journal of Cell Science 117(25) (2004) 6249-6259.

[5] N. Tokesi, A. Lehotzky, I. Horvath, B. Szabo, J. Olah, P. Lau, J. Ovadi, TPPP/p25 promotes tubulin acetylation by inhibiting histone deacetylase 6, J Biol Chem 285(23) (2010) 17896-906.

[6] N.G. Bauer, C. Richter-Landsberg, C. Ffrench-Constant, Role of the oligodendroglial cytoskeleton in differentiation and myelination, Glia 57(16) (2009) 1691-705.

[7] C. Conde, A. Caceres, Microtubule assembly, organization and dynamics in axons and dendrites, Nature reviews. Neuroscience 10(5) (2009) 319-32.

[8] H. de Forges, A. Bouissou, F. Perez, Interplay between microtubule dynamics and intracellular organization, The international journal of biochemistry \& cell biology 44(2) (2012) 266-74.

[9] A. Palazzo, B. Ackerman, G.G. Gundersen, Cell biology: Tubulin acetylation and cell motility, Nature 421(6920) (2003) 230.

[10] E. Lindersson, D. Lundvig, C. Petersen, P. Madsen, J.R. Nyengaard, P. Hojrup, T. Moos, D. Otzen, W.P. Gai, P.C. Blumbergs, P.H. Jensen, p25alpha Stimulates alpha-synuclein aggregation and is colocalized with aggregated alpha-synuclein in alpha-synucleinopathies, J Biol Chem 280(7) (2005) 570315.

[11] G.G. Kovacs, L. Laszlo, J. Kovacs, P.H. Jensen, E. Lindersson, G. Botond, T. Molnar, A. Perczel, F. Hudecz, G. Mezo, A. Erdei, L. Tirian, A. Lehotzky, E. Gelpi, H. Budka, J. Ovadi, Natively unfolded tubulin polymerization promoting protein TPPP/p25 is a common marker of alpha-synucleinopathies, Neurobiology of disease 17(2) (2004) 155-62.

[12] K.A. Jellinger, P.L. Lantos, Papp-Lantos inclusions and the pathogenesis of multiple system atrophy: an update, Acta Neuropathol 119(6) (2010) 657-67.

[13] T. Hasegawa, T. Baba, M. Kobayashi, M. Konno, N. Sugeno, A. Kikuchi, Y. Itoyama, A. Takeda, Role of TPPP/p25 on alpha-synuclein-mediated oligodendroglial degeneration and the protective effect of SIRT2 inhibition in a cellular model of multiple system atrophy, Neurochemistry international $57(8)$ (2010) 857-66.

[14] K. Ota, M. Obayashi, K. Ozaki, S. Ichinose, A. Kakita, M. Tada, H. Takahashi, N. Ando, Y. Eishi, H. Mizusawa, K. Ishikawa, Relocation of p25alpha/tubulin polymerization promoting protein from the nucleus to the perinuclear cytoplasm in the oligodendroglia of sporadic and COQ2 mutant multiple system atrophy, Acta neuropathologica communications 2 (2014) 136.

[15] A. Zotter, J. Olah, E. Hlavanda, A. Bodor, A. Perczel, K. Szigeti, J. Fidy, J. Ovadi, Zn(2)+-induced rearrangement of the disordered TPPP/p25 affects its microtubule assembly and GTPase activity, Biochemistry 50(44) (2011) 9568-78.

[16] A. Zotter, A. Bodor, J. Olah, E. Hlavanda, F. Orosz, A. Perczel, J. Ovadi, Disordered TPPP/p25 binds GTP and displays Mg2+-dependent GTPase activity, FEBS Lett 585(5) (2011) 803-8.

[17] A. Lehotzky, J. Olah, S. Szunyogh, A. Szabo, T. Berki, J. Ovadi, Zinc-induced structural changes of the disordered tppp/p25 inhibits its degradation by the proteasome, Biochim Biophys Acta 1852(1) (2015) 83-91. 
[18] I. Lengyel, J.M. Flinn, T. Peto, D.H. Linkous, K. Cano, A.C. Bird, A. Lanzirotti, C.J. Frederickson, F.J. van Kuijk, High concentration of zinc in sub-retinal pigment epithelial deposits, Exp Eye Res 84(4) (2007) 772-80.

[19] Y. Li, L. Andereggen, K. Yuki, K. Omura, Y. Yin, H.Y. Gilbert, B. Erdogan, M.S. Asdourian, C. Shrock, S. de Lima, U.P. Apfel, Y. Zhuo, M. Hershfinkel, S.J. Lippard, P.A. Rosenberg, L. Benowitz, Mobile zinc increases rapidly in the retina after optic nerve injury and regulates ganglion cell survival and optic nerve regeneration, Proc Natl Acad Sci U S A 114(2) (2017) E209-e218.

[20] J.M. Flinn, P.L. Bozzelli, P.A. Adlard, A.M. Railey, Spatial memory deficits in a mouse model of lateonset Alzheimer's disease are caused by zinc supplementation and correlate with amyloid-beta levels, Frontiers in Aging Neuroscience 6 (2014) 174.

[21] M.M. Bradford, A rapid and sensitive method for the quantitation of microgram quantities of protein utilizing the principle of protein-dye binding, Analytical biochemistry 72 (1976) 248-54.

[22] O. Vincze, N. Tokesi, J. Olah, E. Hlavanda, A. Zotter, I. Horvath, A. Lehotzky, L. Tirian, K.F. Medzihradszky, J. Kovacs, F. Orosz, J. Ovadi, Tubulin polymerization promoting proteins (TPPPs): members of a new family with distinct structures and functions, Biochemistry 45(46) (2006) 13818-26. [23] G.C. Na, S.N. Timasheff, Interaction of vinblastine with calf brain tubulin: multiple equilibria, Biochemistry 25(20) (1986) 6214-22.

[24] M. Medalla, H. Barbas, The Anterior Cingulate Cortex May Enhance Inhibition of Lateral Prefrontal Cortex Via $\mathrm{m} 2$ Cholinergic Receptors at Dual Synaptic Sites, The Journal of neuroscience : the official journal of the Society for Neuroscience 32(44) (2012) 15611-15625.

[25] M. Medalla, J.I. Luebke, Diversity of glutamatergic synaptic strength in lateral prefrontal versus primary visual cortices in the rhesus monkey, J Neurosci 35(1) (2015) 112-27.

[26] L. Ding, K. Yamada, C. Takayama, Y. Inoue, Development of astrocytes in the lamina cribrosa sclerae of the mouse optic nerve, with special reference to myelin formation, Okajimas folia anatomica Japonica 79(5) (2002) 143-57.

[27] C. Ffrench-Constant, R.H. Miller, J.F. Burne, M.C. Raff, Evidence that migratory oligodendrocytetype-2 astrocyte (O-2A) progenitor cells are kept out of the rat retina by a barrier at the eye-end of the optic nerve, Journal of neurocytology 17(1) (1988) 13-25.

[28] V.H. Perry, R.D. Lund, Evidence that the lamina cribrosa prevents intraretinal myelination of retinal ganglion cell axons, Journal of neurocytology 19(2) (1990) 265-72.

[29] S. Haverkamp, H. Wassle, Immunocytochemical analysis of the mouse retina, J Comp Neurol 424(1) (2000) 1-23.

[30] R. Balasubramanian, L. Gan, Development of Retinal Amacrine Cells and Their Dendritic Stratification, Current ophthalmology reports 2(3) (2014) 100-106.

[31] S.C. Neda Barzegar-Befroei, Ashraf Gango, Tunde Peto and Imre Lengyel Zinc and Eye Diseases, IOS Press 76 (2011) 530-553.

[32] G. Age-Related Eye Disease Study Research, A Randomized, Placebo-Controlled, Clinical Trial of High-Dose Supplementation With Vitamins C and E, Beta Carotene, and Zinc for Age-Related Macular Degeneration and Vision Loss: AREDS Report No. 8, Archives of ophthalmology 119(10) (2001) 14171436.

[33] M. Helmstaedter, K.L. Briggman, S.C. Turaga, V. Jain, H.S. Seung, W. Denk, Connectomic reconstruction of the inner plexiform layer in the mouse retina, Nature 500(7461) (2013) 168-74.

[34] H. Wassle, P. Koulen, J.H. Brandstatter, E.L. Fletcher, C.M. Becker, Glycine and GABA receptors in the mammalian retina, Vision research 38(10) (1998) 1411-30.

[35] V. Mangas-Sanjuan, J. Olah, I. Gonzalez-Alvarez, A. Lehotzky, N. Tokesi, M. Bermejo, J. Ovadi, Tubulin acetylation promoting potency and absorption efficacy of deacetylase inhibitors, British journal of pharmacology 172(3) (2015) 829-40.

[36] J. Olah, O. Vincze, D. Virok, D. Simon, Z. Bozso, N. Tokesi, I. Horvath, E. Hlavanda, J. Kovacs, A. Magyar, M. Szucs, F. Orosz, B. Penke, J. Ovadi, Interactions of pathological hallmark proteins: tubulin polymerization promoting protein/p25, beta-amyloid, and alpha-synuclein, J Biol Chem 286(39) (2011) 34088-100. 
[37] N. Tokesi, J. Olah, E. Hlavanda, S. Szunyogh, A. Szabo, F. Babos, A. Magyar, A. Lehotzky, E. Vass, J. Ovadi, Identification of motives mediating alternative functions of the neomorphic moonlighting TPPP/p25, Biochim Biophys Acta 1842(4) (2014) 547-57.

[38] T. Szenasi, J. Olah, A. Szabo, S. Szunyogh, A. Lang, A. Perczel, A. Lehotzky, V.N. Uversky, J. Ovadi, Challenging drug target for Parkinson's disease: Pathological complex of the chameleon TPPP/p25 and alpha-synuclein proteins, Biochim Biophys Acta 1863(1) (2017) 310-323.

[39] M. Ugarte, N.N. Osborne, Recent advances in the understanding of the role of zinc in ocular tissues, Metallomics 6(2) (2014) 189-200.

[40] K. Acevedo, R. Li, P. Soo, R. Suryadinata, B. Sarcevic, V.A. Valova, M.E. Graham, P.J. Robinson, O. Bernard, The phosphorylation of p25/TPPP by LIM kinase 1 inhibits its ability to assemble microtubules, Exp Cell Res 313(20) (2007) 4091-4106.

[41] Q. Liu, G. Tan, N. Levenkova, T. Li, E.N. Pugh, Jr., J.J. Rux, D.W. Speicher, E.A. Pierce, The proteome of the mouse photoreceptor sensory cilium complex, Molecular \& cellular proteomics : MCP 6(8) (2007) 1299-317.

[42] C.L. Schlamp, A.D. Montgomery, C.E. Mac Nair, C. Schuart, D.J. Willmer, R.W. Nickells, Evaluation of the percentage of ganglion cells in the ganglion cell layer of the rodent retina, Mol Vis 19 (2013) 1387-96.

[43] K. Dedek, T. Breuninger, L.P. de Sevilla Muller, S. Maxeiner, K. Schultz, U. Janssen-Bienhold, K. Willecke, T. Euler, R. Weiler, A novel type of interplexiform amacrine cell in the mouse retina, The European journal of neuroscience 30(2) (2009) 217-28.

[44] M. Ishii, K. Morigiwa, M. Takao, S. Nakanishi, Y. Fukuda, O. Mimura, Y. Tsukamoto, Ectopic synaptic ribbons in dendrites of mouse retinal ON- and OFF-bipolar cells, Cell and tissue research 338(3) (2009) 355-75.

[45] S.A. Bloomfield, R.F. Dacheux, Rod vision: pathways and processing in the mammalian retina, Prog Retin Eye Res 20(3) (2001) 351-84.

[46] J.E. Dowling, B.B. Boycott, Organization of the primate retina: electron microscopy, Proceedings of the Royal Society of London. Series B, Biological sciences 166(1002) (1966) 80-111. 


\section{FIGURE LEGENDS}

Figure 1: Immunolocalization of TPPP/p25 in mice retina. (A1) TPPP/p25 immunoreactivity (green) is strongly associated with oligodendrocyte-rich myelinated optic nerve. The intensive TPPP/p25 labelling of cells and projections in the optic nerve stops close to its entry into the eye. On the retinal cross-section, the IPL shows high immunoreactivity. Co-labelling with acetylated tubulin (red) shows acetylation in the optic nerve throughout the nerve-fibre network into the RNFL. (A2) A magnified image of a TPPP/p25 enriched cell of the optic nerve highlights the co-localization (yellow) of TPPP/p25 (green) and acetylated tubulin (red). (B1-4) Retinal cross-section showing immunolocalization of TPPP/p25 in the retina and co-localization with acetylated tubulin. (B1) Cell nuclei staining with DAPI (blue). (B2) TPPP/p25 labelling (green) is present in the RNFL, IPL and in few retinal neurons adjacent to IPL. Immunoreactive cells of INL are indicated by white arrows. (B3) Acetylated tubulin (red) strongly labels the RNFL, IPL, OPL and dispersed filamentous immunoreactivity is present in the nuclear layers. (B4) The merged image shows the co-localisation of TPPP/p25 and acetylated tubulin mainly in the IPL but not in the OPL of the retina. Scale bars $=20 \mu \mathrm{m}$ (C) A maximum projection of a confocal z-stack shows TPPP/p25 immunoreactivity (green) of selected cells (white arrows) both in the INL and GCL and in neurites in the IPL. Scale bar $=10 \mu \mathrm{m}$ (D) Interplexyform projections, extending from IPL to OPL (white arrow), were also TPPP/p25 positive. Scale bar $=10 \mu \mathrm{m}$ (E) The magnified image shows the punctate appearance of TPPP/p25 (green) in the IPL. Double labelling with acetylated tubulin (red) highlighted several acetylated filaments which are not TPPP/p25 immunoreactive. Scale bar = $20 \mu \mathrm{m}$ (F) TPPP/p25 (green) and anti-synaptophysin (red) double labelling showed no co-localisation. Most evidently in sublamina S5, the anti-synaptophysin positive neurites are in close vicinity of the TPPP/p25 immunopositive dendritic network. Scale bar = $20 \mu \mathrm{m}$ (G) The co-labelling of TPPP/p25 (green) and calbindin (magenta) identifies specific layers of the IPL. TPPP/p25 enriched neuritis are predominantly localized in the sublaminas S1, S3 and S5 while calbindin labelled sublaminas S2, S3 and S4. TPPP/p25 positive cells did not appear to co-localise with calbindinh(white arrow). Scale bar $=20 \mu \mathrm{m}$ 

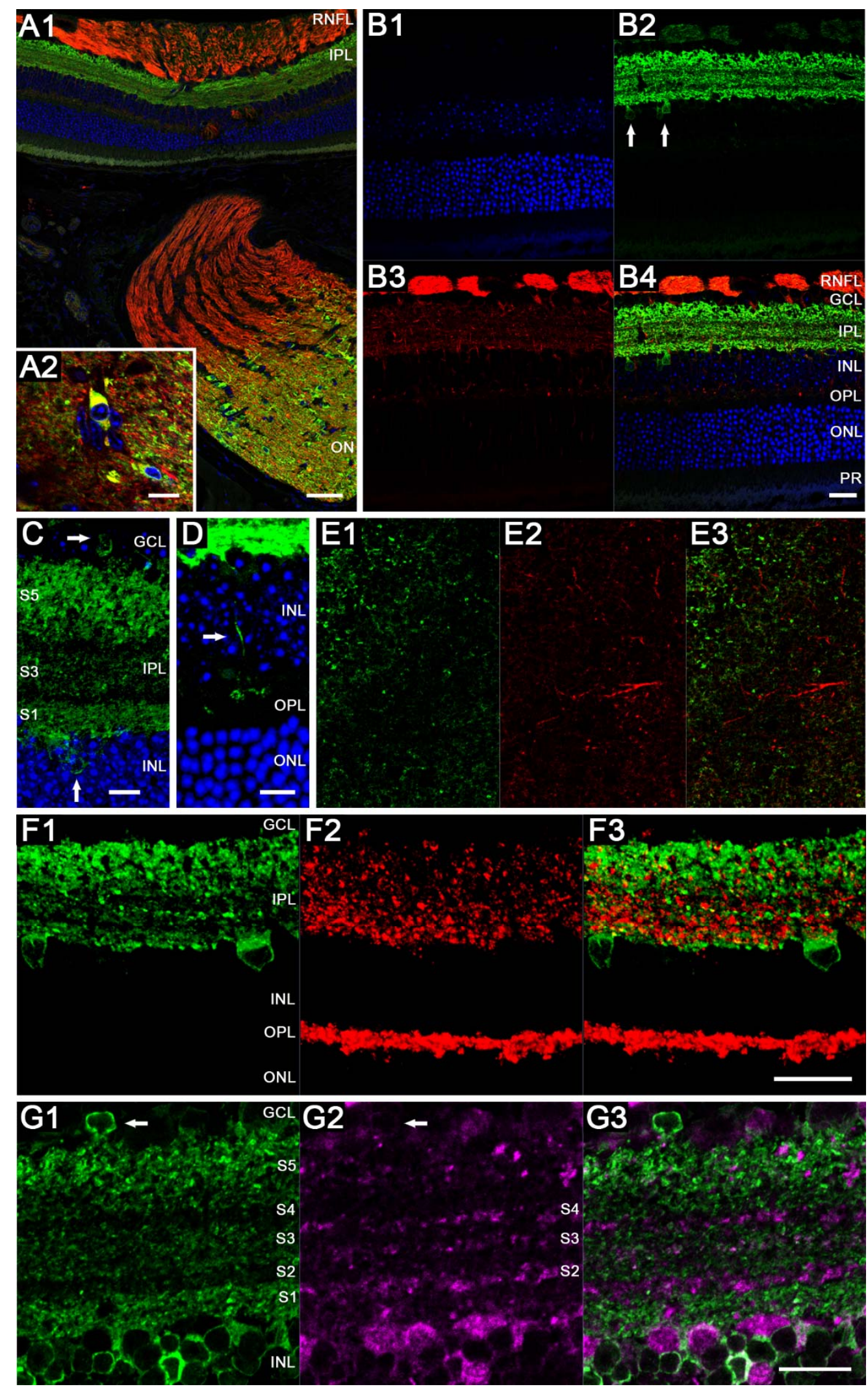
Figure 2: Co-localization of TPPP/p25 and acetylated tubulin in the mice retina. (A) Several oligodendrocytes in the myelinated ON were enriched in both TPPP/p25 (green) and acetylated tubulin (red) immunoreactivity. The nucleus was labelled by DAPI (blue). A line-scan across these cells identified co-localization (white arrowheads) within the cells bodies. The arrow indicates the site of the line-scan and the arrowheads identify corresponding areas on the fluorescent image and the line-scan. (B) A line scan across an amacrine cell and the adjacent S1 sublamina of the IPL showed variable co-localizations. The white arrowheads indicate co-localization while the red arrowhead indicates the lack of co-localization. Scale bar $=10$ $\mu \mathrm{m}$.

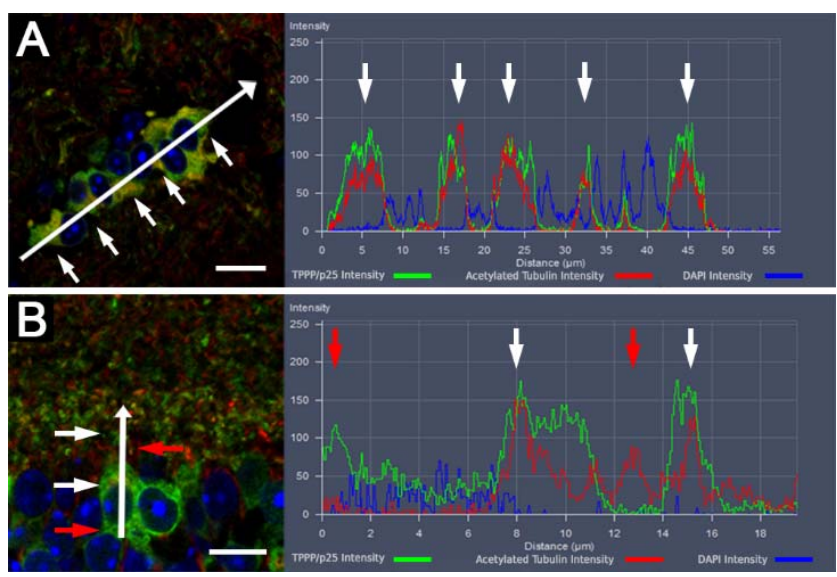


Figure 3: The effects of zinc supplementation on TPPP/p25 levels. Qualitative determination of (A) TPPP/p25 and (B) acetylated tubulin immunoreactivity in the IPL of wild type control in lab water (dashed bars), transgenic on lab water (empty bar) or transgenic animals on zinc supplemented water (black bar) at the central and peripheral retinal locations. Experiments were conducted in triplicates and represented as average $\pm S E M$; * represents $p<0.05$, determined by 2-way Anova.
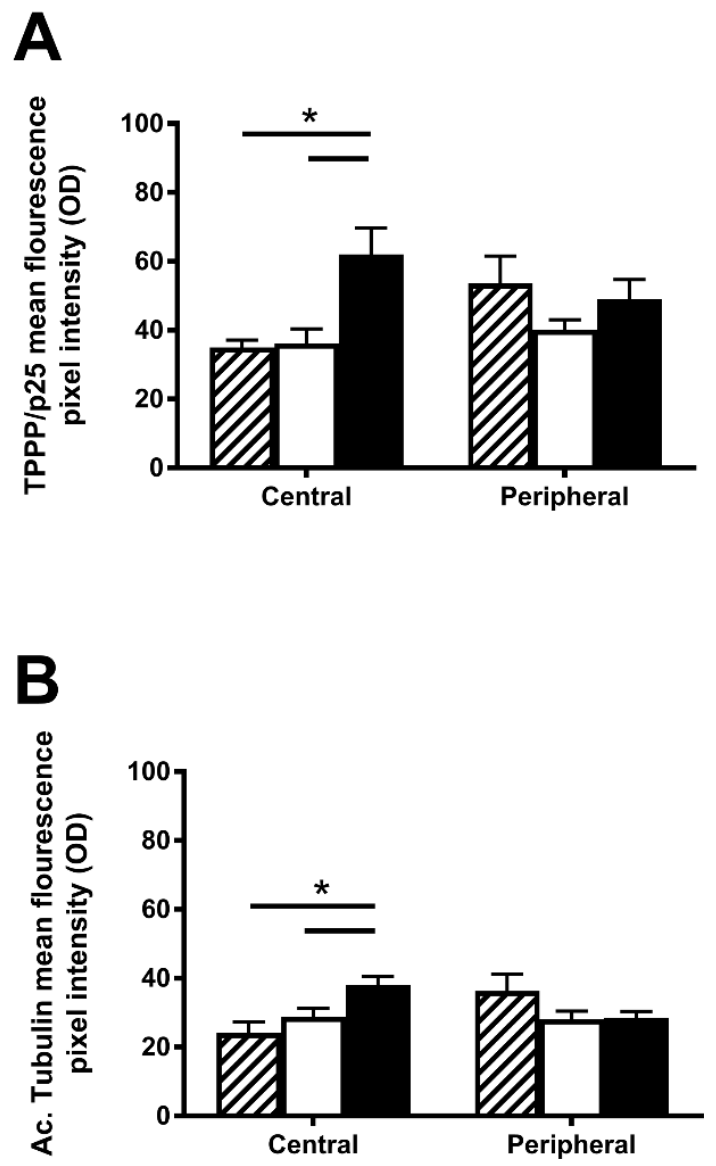
Figure 4: Immunolocalization of TPPP/p25 in human retina. (A) Similar to mice, TPPP/p25 immunolocalization revealed trilaminar distribution in the IPL and scattered immunoreactivity in the OPL in the human retina. (B) TPPP/p25 labelling is present in punctate structures in the IPL and some but not all amacrine cell bodies (white arrows). Interplexyform projections are also present (red arrow). (C) Imaging the amacrine cell layer on a flat-mount retina highlights that only a small proportion of amacrine cells are enriched in TPPP/p25. Scale bar $=20 \mu \mathrm{m}$.

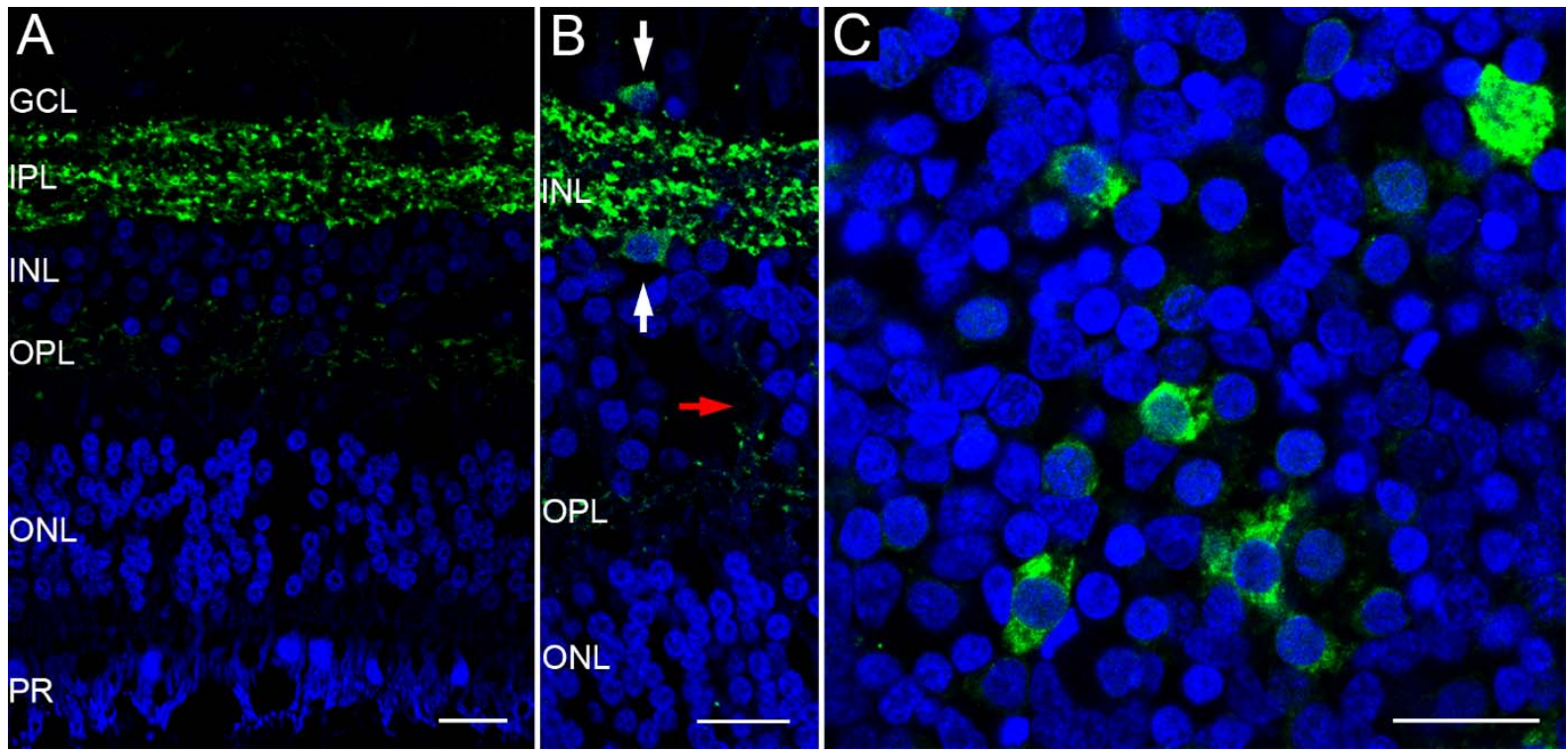


Figure 5: Identification of TPPP/p25 positive amacrine cells based GABA and Glycine content. Sections of human retinas were co-labelled with TPPP/p25 (green) and (A) Glycine (red) or (B) GABA (red). (A) Glycine labelled several cell bodies both in the inner and outer aspect of the IPL (arrows), some of these were TPPP/p25 positive (white arrow) while others did not contain TPPP/p25 (red arrow). (B) Similarly, many GABA-ergic cells were observed on both aspects of IPL (arrows), out of which a some were expressing TPPP/p25 (white arrow), while others did not (red arrow). (C) In the IPL TPPP/p25 (green) and GABA (red) are localized to opposing synaptic structures (red arrow). (D) Immunogold labeling clearly identify TPPP/p25 in the postsynaptic boutons (black arrows), opposite the synaptic vesicle-rich presynaptic terminal. Scale bars on $A, B, C=10 \mu \mathrm{m}$; on $D=10 \mathrm{~nm}$.
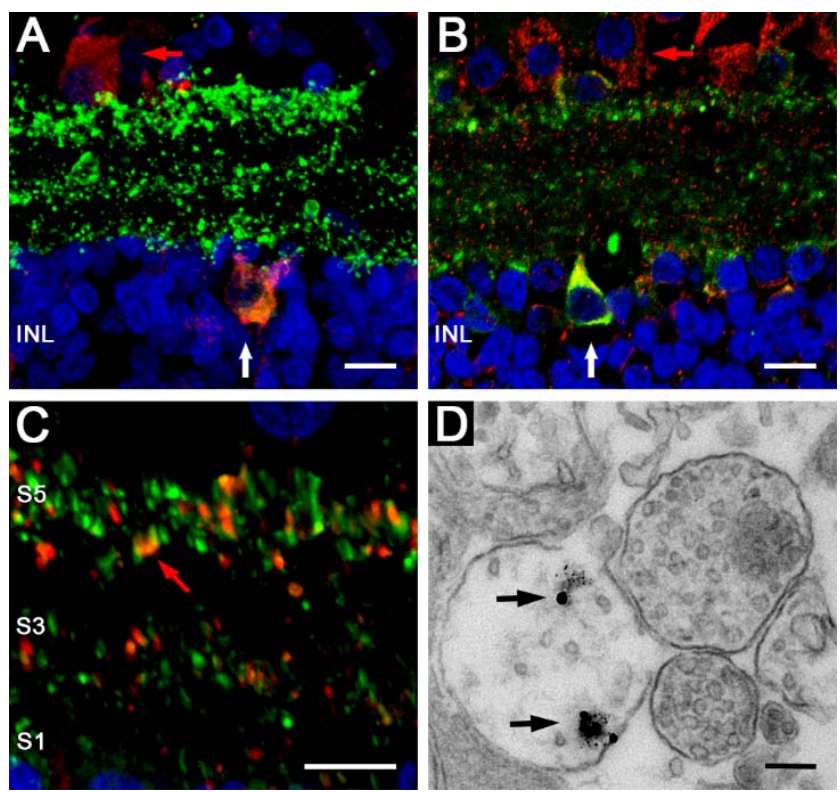
Figure 6: Determination of TPPP/p25 concentration by quantitative Western blot of human retinal extracts. (A) Representative Western blot images: 25 and $50 \mu \mathrm{g}$ retinal homogenate were loaded onto SDS-PAGE along with different concentrations of human recombinant TPPP/p25. (B) Quantification of the Western blot. (C) As a loading control, glyceraldehyde-3phosphate dehydrogenase (GAPDH) was used. (D) Determination of relative concentration of acetylated tubulin. (E) Tubulin concentration was determined by using purified bovine brain tubulin. Concentrations were determined by densitometric analysis using ImageJ v1.48. The data are presented as mean \pm standard deviation, $n=3$. Statistical differences were determined by using two-tailed, unpaired Student's t-test and values were considered to be significant if the $p$ value was $<0.05\left(^{*}\right)$.
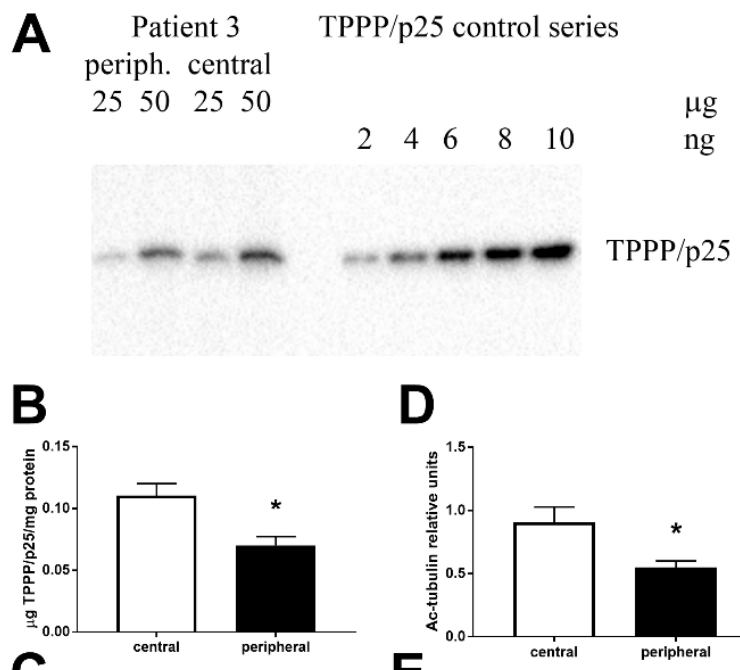

D
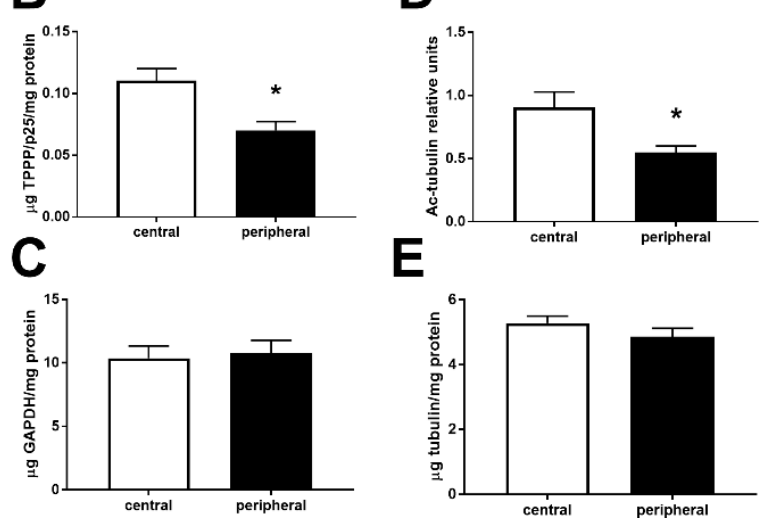

E

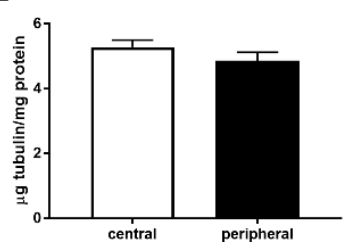




\begin{tabular}{|c|c|c|c|}
\hline Antigen & Host & Working dilution & Source \\
\hline $\begin{array}{l}\text { TPPP/p25 } \\
\text { (Polyclonal) }\end{array}$ & Rat & $\begin{array}{c}1: 200(\mathrm{IHC}) \\
1: 5000 \text { (Western blot) }\end{array}$ & $\begin{array}{c}\text { raised in house } \\
{[1]}\end{array}$ \\
\hline $\begin{array}{c}\text { TPPP/p25 } \\
\text { (Monoclonal) }\end{array}$ & Mouse & $1: 200(\mathrm{IHC})$ & $\begin{array}{c}\text { raised in house } \\
\text { [2] }\end{array}$ \\
\hline $\begin{array}{l}\text { TPPP/p25 } \\
\text { (Polyclonal) }\end{array}$ & Rabbit & 1:100 (Immuno gold) & $\begin{array}{c}\text { Novusbio } \\
\text { NBP1-80962 }\end{array}$ \\
\hline $\begin{array}{l}\text { Acetylated Tu- } \\
\text { bulin (Mono- } \\
\text { clonal) }\end{array}$ & Mouse & $\begin{array}{c}1: 200(\mathrm{IHC}) \\
1: 5000 \text { (Western blot) }\end{array}$ & $\begin{array}{l}\text { Sigma } \\
\text { T6793 }\end{array}$ \\
\hline $\begin{array}{c}\text { Tubulin } \\
\text { (Monoclonal) }\end{array}$ & Mouse & 1:5000 (Western blot) & $\begin{array}{l}\text { Sigma } \\
\text { T9026 }\end{array}$ \\
\hline $\begin{array}{c}\text { Calbindin } \\
\text { (Monoclonal) }\end{array}$ & Rabbit & $1: 2000(\mathrm{IHC})$ & $\begin{array}{l}\text { Sigma } \\
\text { C2724 }\end{array}$ \\
\hline $\begin{array}{c}\text { Synaptophysin } \\
\text { (Monoclonal) }\end{array}$ & Rabbit & 1:300 (IHC) & $\begin{array}{c}\text { MerckMillipore } \\
\text { \#04-1019 }\end{array}$ \\
\hline $\begin{array}{c}\text { GABA } \\
\text { (polyclonal) }\end{array}$ & Rabbit & 1:1000 (IHC) & $\begin{array}{l}\text { Sigma } \\
\text { A2052 }\end{array}$ \\
\hline $\begin{array}{c}\text { Glycine } \\
\text { (polyclonal) }\end{array}$ & Rabbit & 1:100 (IHC) & $\begin{array}{l}\text { donated by D.V.Pow } \\
\text { (raised in house [3]) }\end{array}$ \\
\hline GAPDH & Mouse & 1:5000 (Western blot) & Calbiochem CB1001 \\
\hline \multicolumn{4}{|c|}{$\begin{array}{l}\text { Supplementary table 1. List of primary antibodies used } \\
\text { Antigen specificity, host, source of provenience and working dilution used for } \\
\text { immunohistochemistry (IHC), immune gold staining or western blot are listed for } \\
\text { the primary antibodies. }\end{array}$} \\
\hline
\end{tabular}




\begin{tabular}{ccccc}
\hline Striation & TPPP/p25 & Calbindin & Synaptophysin & Ac-tubulin \\
\hline S5 $(61-100 \%)$ & +++ & + & + & ++ \\
S4 $(53-60 \%)$ & + & + & ++ & ++ \\
S3 $(30-52 \%)$ & ++ & + & ++ & ++ \\
S2 $(23-29 \%)$ & + & & +++ & ++ \\
S1 $(0-22 \%)$ & +++ & & +++
\end{tabular}

Supplementary table 2. Summary of qualitative fluorescence intensities of different proteins in the IPL in mice eye. TPPP/p25 fluorescence intensity identifies 5 striations in the IPL (S1-S5), with the width of striations noted in the brackets. In these striations the immunolabelling intensity of several proteins was assessed and a summary of fluorescence intensities is listed in the table. Intensity gradient for each protein is marked by crosses; the number of crosses between columns are not comparable. 


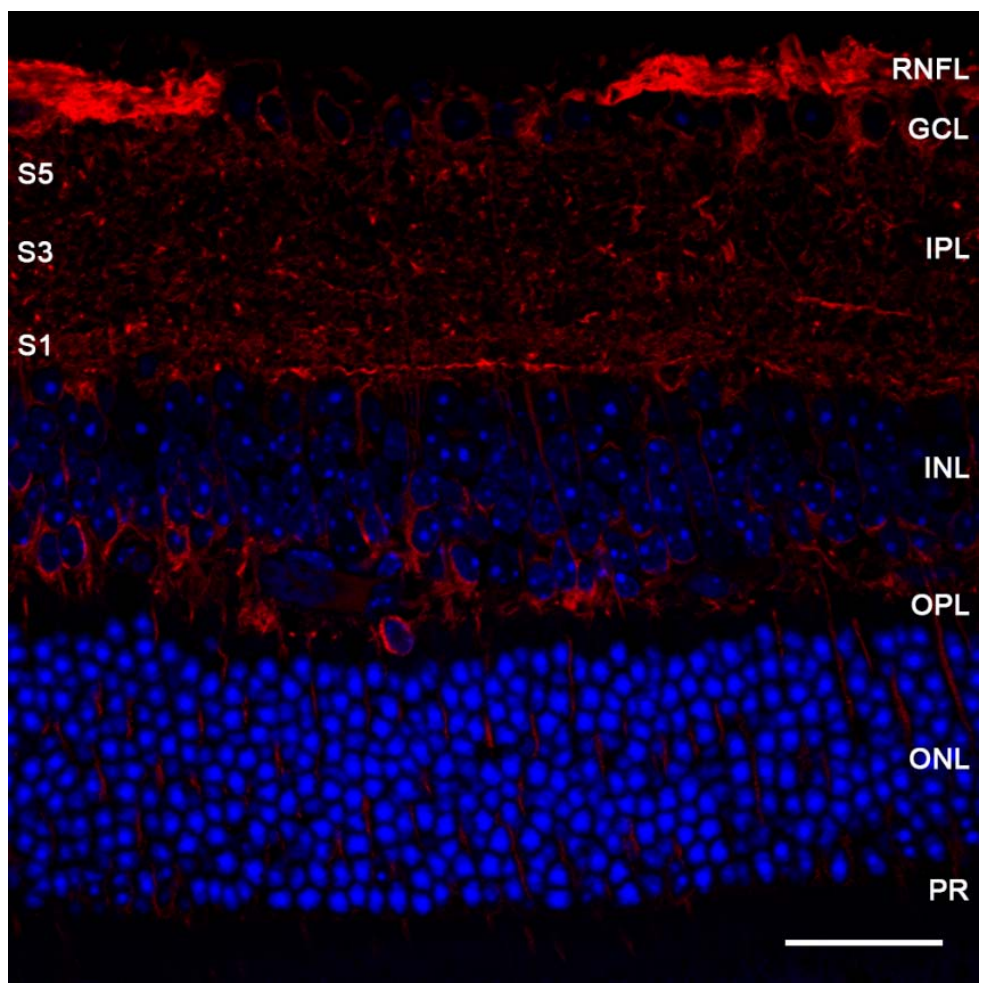

Supplementary figure 1. Immunolocalization of acetylated tubulin in mouse retina.

Acetylated tubulin (red) is visible throughout all layers of the inner retina in a specific distribution: elongated filamentous structures are observed in the RNFL, interlacing projections form a compact functional network in the IPL, and cytoplasmic distribution around nuclei (blue) are all providing stability of the cytoskeleton and synaptic connections. Scale bar $=50 \mu \mathrm{m}$ 


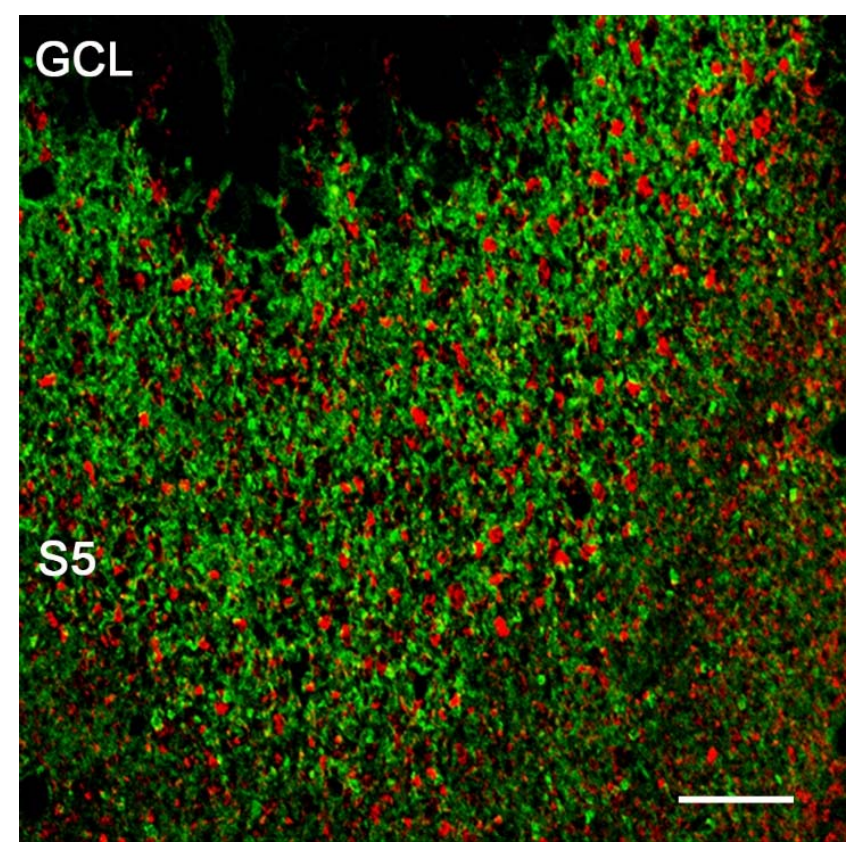

Supplementary figure 2. Immunolocalization of TPPP/p25 and synaptophysin in lamina S5 of mouse retina. A tilted section across the IPL exposed the sublamina S5 containing enlarged synaptophysin labelled presynaptic boutons (red) and TPPP/p25 labelled postsynaptic processes (green). Scale bar $=10 \mu \mathrm{m}$

\section{References:}

[1] G.G. Kovacs, L. Laszlo, J. Kovacs, P.H. Jensen, E. Lindersson, G. Botond, T. Molnar, A. Perczel, F. Hudecz, G. Mezo, A. Erdei, L. Tirian, A. Lehotzky, E. Gelpi, H. Budka, J. Ovadi, Natively unfolded tubulin polymerization promoting protein TPPP/p25 is a common marker of alpha-synucleinopathies, Neurobiology of disease 17(2) (2004) 155-62.

[2] R. Hoftberger, S. Fink, F. Aboul-Enein, G. Botond, J. Olah, T. Berki, J. Ovadi, H. Lassmann, H. Budka, G.G. Kovacs, Tubulin polymerization promoting protein (TPPP/p25) as a marker for oligodendroglial changes in multiple sclerosis, Glia 58(15) (2010) 1847-57.

[3] D.V. Pow, D.K. Crook, Extremely high titre polyclonal antisera against small neurotransmitter molecules: rapid production, characterisation and use in lightand electron-microscopic immunocytochemistry, Journal of Neuroscience Methods 48(1-2) (1993) 51-63. 